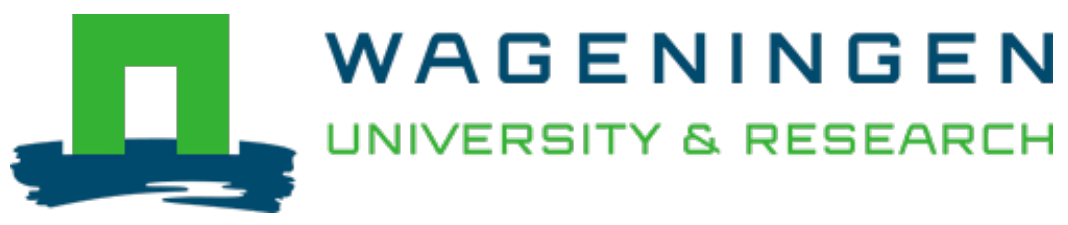

\title{
Application of Mineral Concentrates from Processed Manure
}

Biorefinery of Inorganics: Recovering Mineral Nutrients from Biomass and Organic Waste

Velthof, G.L.; Ehlert, P.A.I.; Schroder, J.J.; Curth-van Middelkoop, J.C.

https://doi.org/10.1002/9781118921487.ch5-5

This publication is made publicly available in the institutional repository of Wageningen University and Research, under the terms of article $25 \mathrm{fa}$ of the Dutch Copyright Act, also known as the Amendment Taverne. This has been done with explicit consent by the author.

Article $25 \mathrm{fa}$ states that the author of a short scientific work funded either wholly or partially by Dutch public funds is entitled to make that work publicly available for no consideration following a reasonable period of time after the work was first published, provided that clear reference is made to the source of the first publication of the work.

This publication is distributed under The Association of Universities in the Netherlands (VSNU) 'Article $25 \mathrm{fa}$ implementation' project. In this project research outputs of researchers employed by Dutch Universities that comply with the legal requirements of Article $25 \mathrm{fa}$ of the Dutch Copyright Act are distributed online and free of cost or other barriers in institutional repositories. Research outputs are distributed six months after their first online publication in the original published version and with proper attribution to the source of the original publication.

You are permitted to download and use the publication for personal purposes. All rights remain with the author(s) and / or copyright owner(s) of this work. Any use of the publication or parts of it other than authorised under article $25 \mathrm{fa}$ of the Dutch Copyright act is prohibited. Wageningen University \& Research and the author(s) of this publication shall not be held responsible or liable for any damages resulting from your (re)use of this publication.

For questions regarding the public availability of this publication please contact openscience.library@wur.nl 


\title{
5.5
}

\section{Application of Mineral Concentrates from Processed Manure}

\author{
Gerard Velthof $^{\mathbf{1}}$, Phillip Ehlert ${ }^{1}$, Jaap Schröder ${ }^{2}$, Jantine van \\ Middelkoop $^{3}$, Wim van Geel ${ }^{2}$, and Gerard Holshof ${ }^{3}$ \\ ${ }^{I}$ WENR, Wageningen University \& Research, Wageningen, The Netherlands \\ ${ }^{2}$ WPR, Wageningen University \& Research, Wageningen, The Netherlands \\ ${ }^{3}$ WLR, Wageningen University \& Research, Wageningen, The Netherlands
}

\subsubsection{Introduction}

Manure is a valuable source of nutrients for crops. However, in regions with intensive livestock farming systems and limited agricultural land, the amount of nutrients available exceeds the nutrient demand of crops. In these regions, the surplus of nitrogen $(\mathrm{N})$ and phosphorus $(\mathrm{P})$ results in an increase in soil nutrient status and high emissions of $\mathrm{N}$ and $\mathrm{P}$ to groundwater, surface water, and the atmosphere [1]. A series of policies and measures have been implemented in the European Union (EU) to decrease emissions of $\mathrm{N}$ and $\mathrm{P}$ from agriculture to the environment [2]. Processing of manure is considered as an option to increase the nutrient use efficiency of manure [3]. One treatment method is separation of livestock slurry into a solid fraction (SF) and a liquid fraction (LF) followed by reverse osmosis (RO) of the LF [4, 5]. The RO decreases the volume of the LF (Chapter 4.3), resulting in a concentrated $\mathrm{N}$-potassium (K) solution ("mineral concentrate"), in which most of the $\mathrm{N}$ is present as ammonium $\left(\mathrm{NH}_{4}{ }^{+}\right)$. The $\mathrm{SF}$ is rich in organic matter $(\mathrm{OM})$ and $\mathrm{P}$, and can be used as a soil amendment. The water removed by RO has low concentrations of nutrients

Biorefinery of Inorganics: Recovering Mineral Nutrients from Biomass and Organic Waste, First Edition. Edited by Erik Meers, Gerard Velthof, Evi Michels and René Rietra.

(C) 2020 John Wiley \& Sons Ltd. Published 2020 by John Wiley \& Sons Ltd. 
and can be discharged to sewer or surface water [6]. The reduction of the volume by RO increases the ability to transport mineral concentrates from areas with high livestock density to arable farming areas. This chapter presents an overview of the nitrogen fertilizer replacement value (NFRV) of mineral concentrates from processed manure, based on a series of studies carried out in the Netherlands. In Section 5.5.2, an assessment is made of the fertilizer value of manure concentrates on the basis of the composition. Section 5.5.3 presents $\mathrm{N}$ fertilizer values obtained in pot and field experiments. Section 5.5.4 deals with $\mathrm{N}$ losses from mineral concentrates as ammonia $\left(\mathrm{NH}_{3}\right)$, nitrous oxide $\left(\mathrm{N}_{2} \mathrm{O}\right)$, and nitrate $\left(\mathrm{NO}_{3}{ }^{-}\right)$.

\subsubsection{Product Characterization}

Table 4.3.1 shows the average composition of mineral concentrates obtained from slurry treatment based on separation and $\mathrm{RO}$. The average total $\mathrm{N}$ content of the concentrates is $8.15 \mathrm{~g} \mathrm{~N} \mathrm{~kg}^{-1}$ product. The $\mathrm{N}$ in mineral concentrates is mainly found in the $\mathrm{NH}_{4}{ }^{+}$form (on average, $90 \%$ of total $\mathrm{N}$ in the concentrate). The remaining $\mathrm{N}$ is organically bound. The $\mathrm{pH}$ of mineral concentrates is high (about $\mathrm{pH}$ 8), thus it is likely that $\mathrm{NH}_{4}{ }^{+}$partly occurs in the form of $\mathrm{NH}_{3}$ in mineral concentrates.

The efficiency of $\mathrm{N}$ in mineral concentrates as a fertilizer depends on the presence and degradability of organic $\mathrm{N}$ and the gaseous $\mathrm{N}$ losses (as $\mathrm{NH}_{3}$ and via denitrification) during and after application [7]. The NFRV of an organic fertilizer is the percentage of the applied $\mathrm{N}$ that has the same effect on crop $\mathrm{N}$ yield as mineral $\mathrm{N}$ fertilizer. In the Netherlands, NFRV is generally determined by comparison with broadcast mineral fertilizer calcium ammonium nitrate (CAN), which is the most commonly used mineral $\mathrm{N}$ fertilizer in the country.

Part of the $\mathrm{N}$ in mineral concentrates becomes available for the crop via $\mathrm{N}$ mineralization. According to fertilizer recommendations in the Netherlands (www.bemestingsadvies .nl; www.kennisakker.nl), it is assumed that the NFRV of organic $\mathrm{N}$ in manure amounts to $20-60 \%$ during the first 12 months after application. The $\mathrm{NH}_{3}$ emission from surface-applied slurry amounts to $69-74 \%$ of applied $\mathrm{NH}_{4}{ }^{+}-\mathrm{N}$ and that from slurry injected in the soil (including injection) is $2-26 \%$ [8]. Assuming that these figures also hold for mineral concentrates, it is estimated that the NFRV of surface-applied mineral concentrates is $25-30 \%$ and that of injected slurry $70-90 \%$ compared to CAN. This theoretical approximation of NFRV has been tested in experiments, the results of which are presented in Section 5.5.3.

The $\mathrm{P}$ content in mineral concentrates is generally low $\left(<0.2 \mathrm{~g} \mathrm{P} \mathrm{kg}^{-1}\right.$; Chapter 4.3$)$, and therefore mineral concentrates have no agronomic value as $\mathrm{P}$ fertilizers.

The $\mathrm{K}$ content in mineral concentrates is about $8 \mathrm{~g} \mathrm{~K} \mathrm{~kg}^{-1}$ (Chapter 4.3). The exact chemical form in which it occurs in mineral concentrates is not known, but based on chemical analysis it is assumed that it is found bound to bicarbonate, chloride, and sulfate and in fatty acids [9]. Therefore, it is likely that the $\mathrm{K}$ in mineral concentrates is fully available to the crop. The supply of $\mathrm{K}$ in mineral concentrate reduces the need for other mineral $\mathrm{K}$ fertilizers. This is particularly advantageous for crops with a high $\mathrm{K}$ demand such as potato and maize. The $\mathrm{K}$ demand of grassland is also high, but is partly met when cattle manure is produced on a farm. An excess supply of $K$ to cattle can cause health problems (grass tetany). The amounts of $\mathrm{K}$ in feed, fertilizer, and manure should hence be taken into consideration when importing mineral concentrates to a dairy farm. 
Mineral concentrates also contain other nutrients, including calcium $(\mathrm{Ca})$, magnesium $(\mathrm{Mg})$, sulfur (S), sodium (Na), and trace elements. If a concentrate is applied at common $\mathrm{N}$ and $\mathrm{K}$ application rates, the supply of most other nutrients is not of agronomic importance. However, the levels of $\mathrm{Na}$ in mineral concentrates are approximately $20-25 \%(\mathrm{w} / \mathrm{w}$ ) that of $\mathrm{K}$ [9]. When using a mineral concentrate as an $\mathrm{N}$ or $\mathrm{K}$ fertilizer, a significant amount of $\mathrm{Na}$ is applied (20-40 $\left.\mathrm{kg} \mathrm{Na} \mathrm{ha}^{-1}\right)$. Na has value in animal feeding, and some arable crops (e.g. sugar beet) respond positively to its application. $\mathrm{S}$ is also a valuable component of mineral concentrate, but the average total $\mathrm{S}$ application rate is low (about $4 \mathrm{~kg}$ per $100 \mathrm{~kg} \mathrm{~N}$ as mineral concentrate, of which about $3 \mathrm{~kg}$ is in the form of sulfate-S). The availability of $\mathrm{S}$ for the crop in mineral concentrates is unknown. The average CL concentration is $3 \mathrm{~g} \mathrm{~kg}^{-1}$ mineral concentrate [9]. Harmful effects to crops of excess $\mathrm{Cl}$ are not an issue when using mineral concentrates, as long as the supply of $\mathrm{Cl}$ with other fertilizers is taken into account.

The contents of the heavy metals $\mathrm{Cd}, \mathrm{Cr}, \mathrm{Ni}, \mathrm{Pb}$, and $\mathrm{As}$ and of organic contaminants such as dioxins, non-ortho PCBs, mono-ortho PCBs, indicator PCBs, organochlorine pesticides residues, polyaromatic hydrocarbons (PAHs), and mineral oil in mineral concentrates are low, and often below the detection limit. These contents meet the standards in the Fertilizer Act of the Netherlands [10]. Consequently, it is unlikely that the use of a mineral concentrate as fertilizer will lead to an unacceptable loading of soil with heavy metals and organic contaminants.

\subsubsection{Agronomic Response}

\subsubsection{Pot Experiments}

Pot experiments to test the NFRV of mineral concentrates, using grass as a test crop and CAN as a reference fertilizer, have been carried out by Ehlert et al. [11], Klop et al. [12], and Rietra and Velthof [13]. CAN consists of $27 \% \mathrm{~N}$, of which half is nitrate and half is ammonium. In these pot experiments, the NFRV of injected mineral concentrate compared to broadcast CAN was on average $91 \%$, and higher than that of injected pig slurry (75\%; Table 5.5.1). These findings are in agreement with the theoretical NFRV estimated from the chemical composition (Section 5.5.2).

In Klop et al.'s experiment [12], grass yields of surface-applied mineral concentrate were low, partly due to scorching of the grass after surface application of the mineral concentrate.

Table 5.5.1 Average nitrogen fertilizer replacement value (NFRV) of injected mineral concentrate and injected pig slurry compared to calcium ammonium nitrate (CAN) (in \%) in pot experiments.

\begin{tabular}{llccccc}
\hline \multirow{2}{*}{ References } & \multirow{2}{*}{ Crop } & \multicolumn{4}{c}{ NFRV, \% of CAN } \\
\cline { 3 - 4 } \cline { 6 - 7 } & & & \multicolumn{2}{c}{ Mineral concentrate } & & \multicolumn{2}{c}{ Pig slurry } \\
\cline { 6 - 7 } \cline { 6 - 7 } & & Injected & Surface-applied & & Injected & Surface-applied \\
\hline$[12]$ & Grass & 96 & 50 & & 79 & 41 \\
{$[11]$} & Grass & 86 & - & & 74 & - \\
{$[11]$} & Swiss chard & 87 & - & & 71 & - \\
{$[13]$} & Grass & 93 & 72 & & 76 & - \\
Average & & 91 & - & & 75 & - \\
\hline
\end{tabular}


The same held with surface-applied pig slurry. Scorching did not occur after injection of mineral concentrate or pig slurry or after surface-application of CAN. Deposition of urine during grazing has also been shown to induce scorching of grass [14]. Probably, salt, $\mathrm{NH}_{3}$, and volatile fatty acids concentrations near the grass roots were too high after surface application of mineral concentrate and pig slurry but not after injection. Part of the difference between surface application and injection is due to differences in $\mathrm{NH}_{3}$ emissions. The NFRV of pig slurry was only $41 \%$ after surface application, and increased to $79 \%$ when injected [12]. Measurements showed that $\mathrm{NH}_{3}$ emission was much lower from injected concentrate than from surface-applied concentrate. Emission of $\mathrm{N}_{2} \mathrm{O}$ from mineral concentrate was higher than from CAN, but lower than from pig slurry.

In Ehlert et al.'s experiment [11], the NFRV of mineral concentrate was tested with perennial rye grass and Swiss chard and with different types of mineral $\mathrm{N}$ fertilizer. The NFRV of mineral concentrate compared to CAN was on average $87 \%$. The NFRV of liquid ammonium nitrate (AN), ammonium sulfate (AS), and ammonium chloride was on average $100 \%$ compared to CAN. This indicates that the efficiency of solid ammonium fertilizers was higher than that of mineral concentrate in this experiment. The NFRV of urea was somewhat lower (except when applied to grass on a sandy soil), probably due to $\mathrm{NH}_{3}$ emission [15].

In Rietra and Velthof's experiment [13], the effects of soil moisture content and acidification of mineral concentrate on NFRV were tested. Acidification is a measure to decrease $\mathrm{NH}_{3}$ emission [16]. The NFRV of injected concentrates (84-93\%, with the highest NFRV at the highest moisture content) was significantly higher than that of surface-applied concentrate (64-79\%). The NFRV of acidified concentrate was similar to that of CAN. Measurements showed that acidification minimized $\mathrm{NH}_{3}$ emission.

\subsubsection{Field Experiments}

Field experiments in the Netherlands show NFRVs of injected (to a depth of $5 \mathrm{~cm}$ ) mineral concentrates ranging from 54 to $84 \%$ compared to broadcast CAN (Table 5.5.2). The lowest NFRV, 54\%, was observed on grassland in 2009. An explanation for this relative outlier is as yet lacking. Averaged over all experiments, the NFRV of mineral concentrate compared to CAN was $79 \%$ on arable land and $71 \%$ on grassland. These values are lower than those obtained in the pot experiments (Table 5.5.2) and at the lower end of the theoretically estimated NFRV values of 70-90\% (Section 5.5.2). Van Geel et al. [21] also determined the NFRV in field experiments, with a less detailed set-up than the experiments described in Table 5.5.2. Their results showed a wide range in NFRV (0-130\%). In 20 experiments, the NFRV of mineral concentrate was similar to CAN, in 10 it was lower than CAN, and in 1 it was higher than CAN [21].

The NFRV of mineral concentrates was higher (79-117\%, average 93\%) when compared to liquid ammonium nitrate injected with the same equipment as mineral concentrate. Clearly, the application method and form of fertilizer affect $\mathrm{N}$ use efficiency; that is, the $\mathrm{N}$ use efficiency of an injected liquid $\mathrm{N}$ fertilizer (liquid ammonium nitrate and mineral concentrate) was lower than that of broadcast CAN prills. The distribution of $\mathrm{N}$ in the soil differed between broadcast-applied CAN and injected liquid fertilizers, and this could be a factor in the differences in $\mathrm{N}$ use efficiency between $\mathrm{CAN}$ and the liquid fertilizers. 
Table 5.5.2 Average nitrogen fertilizer replacement value (NFRV) of injected mineral concentrate compared to calcium ammonium nitrate (CAN) or liquid ammonium nitrate (AN) (in \%) in field experiments.

\begin{tabular}{|c|c|c|c|c|c|}
\hline \multirow[t]{2}{*}{ Crop } & \multirow[t]{2}{*}{ Year } & \multirow[t]{2}{*}{ Soil type } & \multicolumn{2}{|c|}{ NFRV, \% } & \multirow[t]{2}{*}{ References } \\
\hline & & & $\begin{array}{c}\text { Compared to } \\
\text { CAN }\end{array}$ & $\begin{array}{l}\text { Compared to } \\
\text { liquid AN }\end{array}$ & \\
\hline Potato & 2009 & Clay & 76 & & [17] \\
\hline Potato & 2009 & Sand & 84 & & [17] \\
\hline Potato & 2010 & Clay & 75 & 117 & {$[17,18]$} \\
\hline Potato & 2010 & Sand & 81 & & [17] \\
\hline Maize & 2010 & Sand & 72 & & [19] \\
\hline Maize & 2011 & Sand & 84 & & [19] \\
\hline Grassland & 2009 & Sand/clay & $54^{a}$ & 86 & [20] \\
\hline Grassland & 2010 & Sand/clay & $71^{a}$ & 102 & [20] \\
\hline Grassland & 2011 & Sand & $80^{a}$ & 79 & [20] \\
\hline Grassland & 2012 & Sand & $81^{a}$ & 83 & [20] \\
\hline
\end{tabular}

${ }^{a}$ For each year, the average NFRV of two to four experiments is included.

The results of the experiments indicate that there is scope to increase NFRV in the field by optimizing the use of mineral concentrate via low $\mathrm{NH}_{3}$ emission application techniques and by decreasing the organic $\mathrm{N}$ content of mineral concentrate.

\subsubsection{Risk of Nitrogen Losses}

\subsubsection{Ammonia Emission}

Mineral concentrate is an $\mathrm{NH}_{4}{ }^{+}$-containing fertilizer with a high $\mathrm{pH}$ (about 8), and therefore it carries a risk of $\mathrm{NH}_{3}$ emission. Injection into the soil is a well-known $\mathrm{NH}_{3}$ emission abatement technique [22]. A review by Hou et al. [23] showed that emissions of $\mathrm{NH}_{3}$ from slurries following band spreading, incorporation, and injection were 55\% (range: 37-67\%), 70\% (50-82\%), and 80\% (72-86\%) lower than those from surface applied manures, respectively.

In a series of incubation studies, the $\mathrm{NH}_{3}$ emissions from untreated pig slurry, mineral concentrate, mineral fertilizers, and the SF of separated slurry were quantified [24]. The products were both surface-applied and injected in the soil at $5 \mathrm{~cm}$ depth. Surface application of mineral concentrate, pig slurry, and urea resulted in high $\mathrm{NH}_{3}$ emissions (Figure 5.5.1). The $\mathrm{NH}_{3}$ emission from injected mineral concentrate was low, similar to that of surface-applied CAN (Figure 5.5.1). Averaged over three incubation tests, the $\mathrm{NH}_{3}$ emission from injected mineral concentrate was significantly lower than that of injected pig slurry [24].

In a review, Hou et al. [23] found significantly lower $\mathrm{NH}_{3}$ emissions (reduction with $18 \%$ based on 44 observations) for separated LF relative to untreated slurry. $\mathrm{The}^{\mathrm{NH}} \mathrm{N}_{3}$ emissions from mineral concentrates and LF were not determined in the same experiment, so it is not clear if $\mathrm{NH}_{3}$ emission from mineral concentrates differs from that from $\mathrm{LF}$ under the same conditions. Differences in $\mathrm{NH}_{3}$ emission may be expected because of the higher $\mathrm{NH}_{4}{ }^{+}$ concentration of mineral concentrates compared to the LF or the lower water content of 


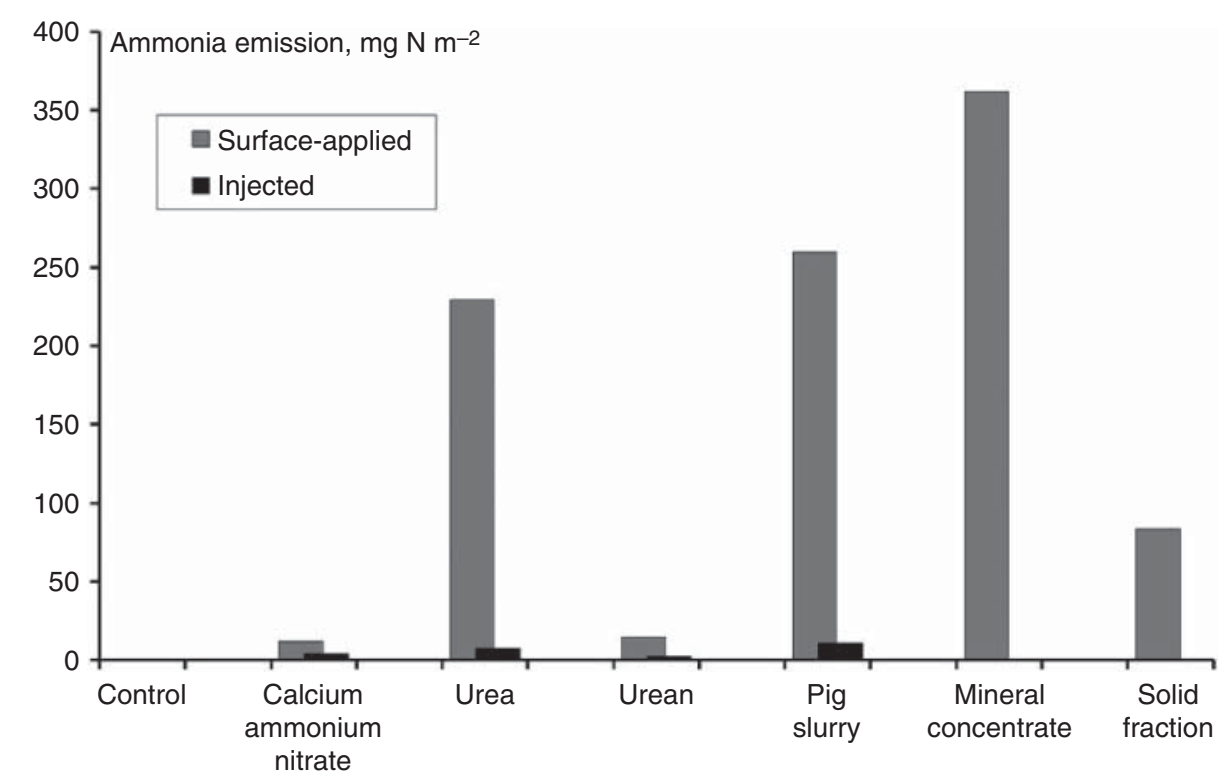

Figure 5.5.1 $\mathrm{NH}_{3}$ emissions from calcium ammonium nitrate (CAN), urea, urean (liquid mixture of urea and ammonium nitrate), pig slurry, mineral concentrate, and the SF of separated slurry applied at equal amounts of total $N$. All fertilizers and manures were both surface-applied and injected (indicated as incorporated). Source: Results of an incubation experiment with arable sandy soil by Velthof and Hummelink [24].

mineral concentrates, as a result of which the infiltration rate into the soil may be reduced. Because of these differences, the $\mathrm{NH}_{4}{ }^{+}$concentration gradient at the liquid-air interface will be greater after application of mineral concentrate than after application of LF.

Field experiments in 2010 showed that the $\mathrm{NH}_{3}$ emission after sod injection in cereals was $3 \%$ of the applied $\mathrm{NH}_{4}{ }^{+}-\mathrm{N}$ in the mineral concentrate, or $12 \%$ when applied via trailing hoses [25]. The $\mathrm{NH}_{3}$ emission from mineral concentrate applied to grassland via sod injection averaged $8 \%$ of the applied $\mathrm{NH}_{4}{ }^{+}-\mathrm{N}$. These measurements were carried out in just one year, and thus the emission factors cannot be generally applied, as weather conditions have a major effect on $\mathrm{NH}_{3}$ emission [26].

The risk of $\mathrm{NH}_{3}$ emission from applied mineral concentrate is probably higher when applied to soils containing lime than to neutral or acidic soils, as is the case for any other $\mathrm{NH}_{4}{ }^{+}$-based mineral fertilizer [15]. Additional $\mathrm{NH}_{3}$ abatement techniques may be applied to decrease $\mathrm{NH}_{3}$ emission and increase $\mathrm{N}$ efficiency. Rietra and Velthof [13] showed in a pot experiment that acidification of mineral concentrates minimized $\mathrm{NH}_{3}$ emission. The NFRV of acidified mineral concentrate was equal to that of CAN.

\subsubsection{Nitrous Oxide Emission}

In a series of incubation studies, Velthof and Hummelink [24] quantified $\mathrm{N}_{2} \mathrm{O}$ emissions from untreated pig slurry, mineral concentrate, and mineral fertilizers (see Figure 5.5.2 for the results of the experiment with grassland soils). The average $\mathrm{N}_{2} \mathrm{O}$ emission of injected mineral concentrate was higher than the $\mathrm{N}_{2} \mathrm{O}$ emission from a similar $\mathrm{N}$ rate of 


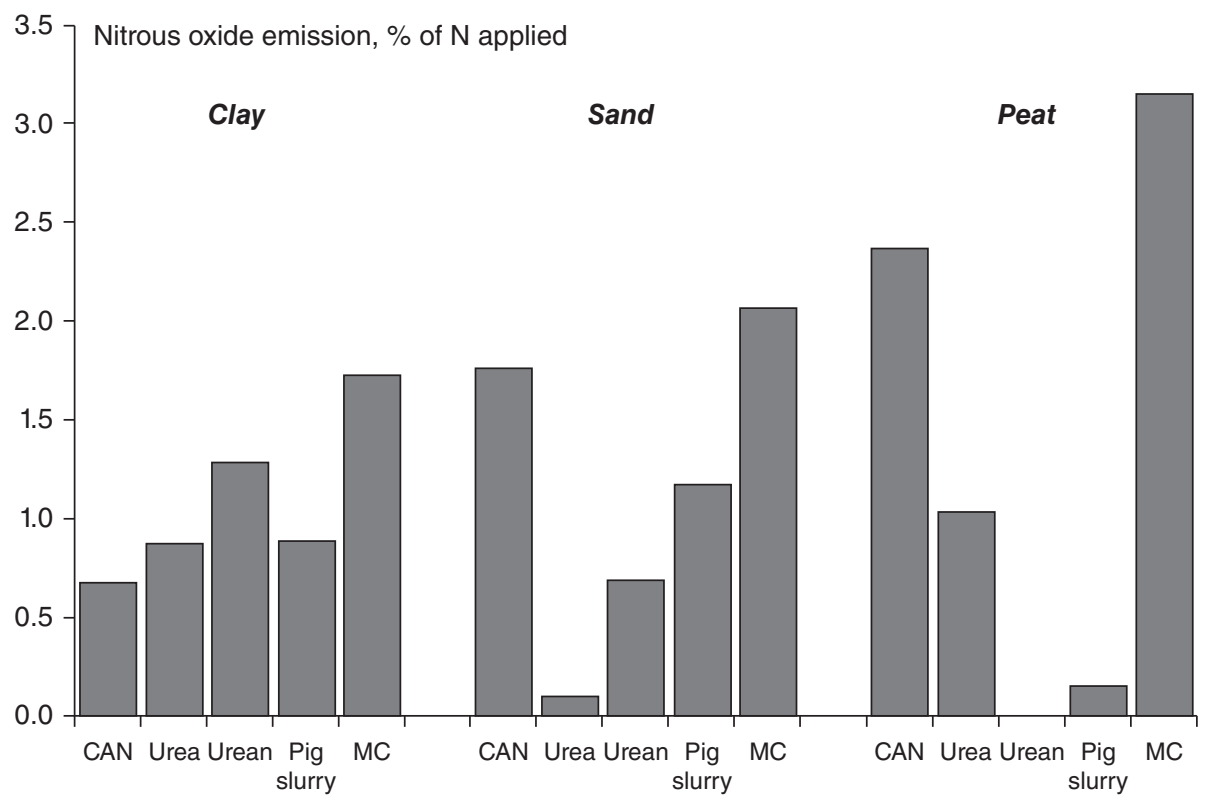

Figure 5.5.2 $\mathrm{N}_{2} \mathrm{O}$ emission factors as per cent of $\mathrm{N}$ applied for calcium ammonium nitrate (CAN), urea, urean, pig slurry, and mineral concentrate (MC) applied to intact grassland columns (PVC columns with a diameter of $10 \mathrm{~cm}$ and height of $10 \mathrm{~cm}$ ) from clay, sand, and peat soils. The application rate was equivalent to $170 \mathrm{~kg} \mathrm{Nha}^{-1}$. CAN, urea, and urean were surface-applied and the pig slurry and mineral concentrates were injected in a row at $5 \mathrm{~cm}$ depth with a knife. The soil moisture content was kept at field capacity and incubation was carried out at $20^{\circ} \mathrm{C}$. Source: Results of a 14-day experiment under controlled conditions by Velthof and Hummelink [24].

surface-applied CAN [24]. The $\mathrm{N}_{2} \mathrm{O}$ emission from mineral concentrate was approximately 1.5-fold higher than that from untreated pig slurry, averaged over all studies and application techniques [24]. The injection of mineral concentrate and pig slurry resulted in higher $\mathrm{N}_{2} \mathrm{O}$ emissions than surface application.

Both nitrification and denitrification may be sources of $\mathrm{N}_{2} \mathrm{O}$ after application of mineral concentrates to a soil. Application of mineral concentrates may strongly increase concentrations of $\mathrm{NH}_{3}$ in the soil. Ammonia is toxic for nitrifying organisms. A high $\mathrm{NH}_{3}$ concentration in soil may thus inhibit nitrification, leading to the production of nitrite and $\mathrm{N}_{2} \mathrm{O}[27,28]$. These effects are likely to be similar to those found in urine patches [29] and after application of anhydrous ammonia as fertilizer [30]. As for denitrification-related $\mathrm{N}_{2} \mathrm{O}$ production, it must be noted that mineral concentrates contain organic carbon, including volatile fatty acids [11]. When degradable OM is applied to a nitrate containing soil under wet conditions, denitrifying bacteria may use the carbon as an energy source, and nitrate can be transformed into gaseous $\mathrm{N}_{2} \mathrm{O}$ and $\mathrm{N}_{2}$. Paul and Beauchamp [31] showed that volatile fatty acids are effective energy sources for denitrifiers. Accordingly, Ehlert et al. [11] found that application of mineral concentrates to soil increased potential denitrification. The higher $\mathrm{N}_{2} \mathrm{O}$ emission from injected mineral concentrate compared with surface-applied mineral concentrate is probably related to the lower oxygen concentrations in the soil, and the higher $\mathrm{N}$ concentrations after injection [32]. 


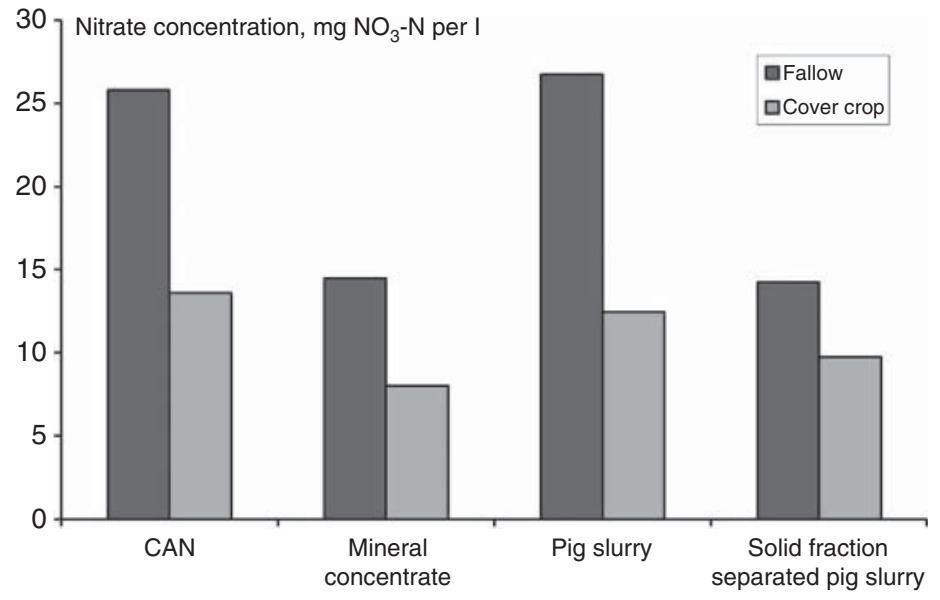

Figure 5.5.3 Average $\mathrm{NO}_{3}{ }^{-}-\mathrm{N}$ concentration $\left(\mathrm{mg} \mathrm{NO}_{3}{ }^{-}-\mathrm{N}_{\text {per }}{ }^{-1}\right)$ in the upper groundwater in a field experiment with maize on sandy soil carried out in 2010 and 2011. Calcium ammonium nitrate (CAN), mineral concentrate, pig slurry, and the solid fraction (SF) of separated pig slurry were applied at $150 \mathrm{~kg} \mathrm{Nha}{ }^{-1}$. The experiment was carried out with and without a rye winter crop [19].

The amount of $\mathrm{N}$ lost via $\mathrm{N}_{2} \mathrm{O}$ emission is low (usually less than $2 \%$ of the $\mathrm{N}$ applied as fertilizer or manure; [33]). Similar amounts will be lost in the form of $\mathrm{NO}_{\mathrm{x}}$ [34]. Emissions of $\mathrm{N}_{2}$ can be much higher than those of $\mathrm{N}_{2} \mathrm{O}$, especially under wet conditions [35]. The total gaseous $\mathrm{N}$ losses as $\mathrm{N}_{2} \mathrm{O}, \mathrm{NO}_{\mathrm{X}}$, and $\mathrm{N}_{2}$ by nitrification and denitrification may significantly affect the $\mathrm{N}$ efficiency of mineral concentrates.

\subsubsection{Nitrate Leaching}

Mineral $\mathrm{N}$ in the soil in the fall is an indicator for the risk of $\mathrm{NO}_{3}{ }^{-}$leaching in winter in the Netherlands [36]. Measurements of mineral $\mathrm{N}$ contents in the soil after harvest in fall showed overall no differences between CAN and mineral concentrates in experiments with potato, maize, and grassland [17-20]. These results suggest that the use of mineral concentrate does not increase the risk of $\mathrm{NO}_{3}{ }^{-}$leaching compared to CAN.

Measurements in 2010 and 2011 of the $\mathrm{NO}_{3}{ }^{-}$concentration in the groundwater of the field experiments with maize showed that it was on average lower in the plots to which mineral concentrate was applied than in those that received CAN and pig slurry (Figure 5.5.3). A winter cover crop significantly reduced leaching of $\mathrm{NO}_{3}{ }^{-}$. In these maize experiments, the NFRV of mineral concentrate was $72-84 \%$ that of CAN. The lower NFRV did not increase $\mathrm{N}$ leaching losses from concentrates compared to CAN, however. Immobilization of mineral $\mathrm{N}$ probably didn't occur either [11]. A reduced availability of $\mathrm{N}$ from mineral concentrate due to an incomplete mineralization is also not likely, given the low content (5-10\%) of organic $\mathrm{N}$ in mineral concentrates. These results indicate that the lower NFRV of mineral concentrates compared to $\mathrm{CAN}$ in these experiments was most likely related to gaseous $\mathrm{N}$ losses by denitrification and $\mathrm{NH}_{3}$ emission. 
Measurements of $\mathrm{NO}_{3}{ }^{-}$concentrations in the upper groundwater in a grassland experiment in 2012 showed no clear differences in nitrate concentration between mineral concentrate and CAN [20]. In an experiment by Schils et al. [37], $\mathrm{NO}_{3}{ }^{-}$concentration in upper groundwater was measured in 10 maize and 20 grassland farm fields. In one part of each field, mineral fertilizer and cattle slurry were applied, while in another part, mineral fertilizer was replaced by mineral concentrate at a comparable total $\mathrm{N}$ rate. The variation in $\mathrm{NO}_{3}{ }^{-}$concentration was large, and concentrations were higher in maize land than in grassland. There was no statistically significant difference in $\mathrm{NO}_{3}{ }^{-}$concentration between the two nutrient-management treatments.

These studies show that the risk of $\mathrm{NO}_{3}{ }^{-}$leaching from applied mineral concentrates is similar to or lower than that with CAN, for both grassland and arable land. The N leaching losses from slurries were higher than those from mineral concentrate, probably due to release of mineral $\mathrm{N}$ by mineralization outside the growing period of the crop. The organic $\mathrm{N}$ contents of mineral concentrates were much lower than those of untreated slurries.

\subsubsection{Conclusion}

Mineral concentrates are $\mathrm{N}-\mathrm{K}$ fertilizers produced by RO of the LF of separated livestock slurry. About $90 \%$ of the $\mathrm{N}$ in mineral concentrate is present as ammonium, the other $10 \%$ as organic N. Pot experiments showed that the NFRV of injected mineral concentrate was on average $91 \%$ that of CAN, and higher than that of injected pig slurry (75\%). In field experiments in the Netherlands, NFRVs of injected mineral concentrates ranged from 54 to $84 \%$ compared to broadcast CAN. Injection of mineral concentrate into the soil strongly decreased $\mathrm{NH}_{3}$ emission in incubation experiments, but increased $\mathrm{N}_{2} \mathrm{O}$ emission. Field measurements show that the risk of nitrate leaching from applied mineral concentrates is similar to or lower than that from $\mathrm{CAN}$ and untreated manure. Obviously, $\mathrm{NH}_{3}$ emission and denitrification are the dominant $\mathrm{N}$-loss pathways after application of mineral concentrate. Losses of $\mathrm{N}$ after such applications can be decreased and NFRV can be increased by using low- $\mathrm{NH}_{3}$-emission application techniques, acidification, and a reduction of the organic $\mathrm{N}$ content of the concentrate.

\section{References}

1. Velthof, G.L., Lesschen, J.P., Webb, J. et al. (2014). The impact of the nitrates directive on nitrogen emissions from agriculture in the EU-27 during 2000-2008. Science of the Total Environment 15: 468-469.

2. Oenema, O., Bleeker, A., Braathen, N.A. et al. (2011). Nitrogen in current European policies. In: The European Nitrogen Assessment (eds. M.A. Sutton, C.M. Howard, J.W. Erisman, et al.), 62-81. Cambridge: Cambridge University Press.

3. Burton, C.H. (2007). The potential contribution of separation technologies to the management of livestock manure. Livestock Science 112: 208-216.

4. Thörneby, L., Persson, K., and Trägårdh, G. (1999). Treatment of liquid effluents from dairy cattle and pigs using reverse osmosis. Journal of Agricultural Engineering Research 73: 159-170.

5. Ledda, C., Schievano, A., Salati, S., and Adani, F. (2013). Nitrogen and water recovery from animal slurries by a new integrated ultrafiltration, reverse osmosis and cold stripping process: a case study. Water Research 47: 6157-6166. 
6. Hoeksma, P., de Buisonjé, F.E. (2012) Mineral Concentrates from Animal Slurry. Monitoring of the Pilot Plants in 2011 [Dutch]. Report 626, Livestock Research, Wageningen.

7. Birkmose, T.S. (2009). Nitrogen Recovery from Organic Manures: Improved Slurry Application Techniques and Treatment; the Danish Scenario. York: International Fertilizer Society.

8. Huijsmans, J.F.M. and Schils, R.L.M. (2009). Ammonia and Nitrous Oxide Emissions Following Field-Application of Manure: State of Art Measurements in the Netherlands. York: International Fertilizer Society.

9. Ehlert, P.A.I., Hoeksma, P. (2011) Agronomic and Environmental Perspectives of Mineral Concentrates. Study in the Framework of the Pilot Mineral Concentrates [Dutch]. Report 2185, Alterra, Wageningen.

10. Ehlert, P.A.I., Hoeksma, P., Velthof, G.L. (2009) Inorganic and Organic Pollutants in Mineral Concentrates. Results of First Screening [Dutch]. Report 256, Animal Sciences Group, Wageningen.

11. Ehlert, P.A.I., Nelemans, J.A., Velthof G.L. (2012) Nitrogen Efficiency and Losses by Denitrification and Nitrogen Immobilisation Obtained under Controlled Conditions [Dutch]. Report 2314, Alterra, Wageningen.

12. Klop, G., Velthof, G.L., and van Groenigen, J.W. (2012). Application technique affects the potential of mineral concentrates from livestock manure to replace inorganic nitrogen fertilizer. Soil Use and Management 28: 468-477.

13. Rietra, R.P.J.J., Velthof, G.L. (2014) Nitrogen Efficiency of Mineral Concentrate under Controlled Conditions. Effects of Acidification, Moisture, and Application Technique [Dutch]. Report 2518, Alterra, Wageningen.

14. Lantinga, E.A., Keuning, J.A., Groenwold, J., and Deenen, P.J.A.G. (1987). Distribution of excreted nitrogen by grazing cattle and its effect on sward quality herbage production and utilization. In: Animal Manure on Grassland and Fodder Crops: Fertilizer or Waste? (eds. H.G. Van der Meer, R.J. Unwin, T.A. Van Dijk and G.C. Ennik), 103-117. Dordrecht: Martinus Nijhoff.

15. Sommer, S.G., Schjoerring, J.K., and Denmead, O.T. (2004). Ammonia emission from mineral fertilizers and fertilized crops. Advances in Agronomy 82: 557-622.

16. Kai, P., Pedersen, P., Jensen, J.E. et al. (2008). A whole-farm assessment of the efficacy of slurry acidification in reducing ammonia emissions. European Journal of Agronomy 28: 148-154.

17. Schröder, J.J., de Visser, W., Assinck, F.B.T. et al. (2014). Nitrogen fertilizer replacement value of the liquid fraction of separated livestock slurries applied to potatoes and silage maize. Communications in Soil Science and Plant Analysis 45: 73-85.

18. Van Geel W., van den Berg, W., van Dijk, W. (2012) Nitrogen Efficiency of Mineral Concentrates Applied to Potatoes. Report of Field Research in 2009 and 2010 [Dutch]. Report 475, PPO, Wageningen.

19. Schröder, J.J., de Visser, W., Assinck, F.B.T., and Velthof, G.L. (2013). Effects of short-term nitrogen supply from livestock manures and cover cropping on silage maize production and nitrate leaching. Soil Use and Management 29: 151-160.

20. Holshof G., van Middelkoop, J.C. (2014) Nitrogen Efficiency of Mineral Concentrates Applied to Grassland. Field Experiments 2012 and Overall Analysis [Dutch]. Report 769, Livestock Research 769, Wageningen.

21. Van Geel, W, van den Berg, W., van Dijk, W., Wustman, R. (2012) Additional Research Mineral Concentrates 2009-2011 on Arable Land and Grassland. Summary of the Results of the Field Experiments and Determination of the Nitrogen Use Efficiency [Dutch]. Report 476, PPO, Wageningen.

22. Bittman, S., Dedina, M., Howard, C.M. et al. (eds.) (2014). Options for Ammonia Mitigation: Guidance from the UNECE Task Force on Reactive Nitrogen. Edinburgh: Centre for Ecology and Hydrology.

23. Hou, Y., Velthof, G.L., and Oenema, O. (2015). Mitigation of ammonia, nitrous oxide and methane emissions from manure management chains: a meta-analysis and integrated assessment. Global Change Biology 21: 1293-1312. 
24. Velthof, G.L., Hummelink, E. (2011) Ammonia and Nitrous Oxide Emission after Application of Mineral Concentrates. Results of Laboratory Studies as Part of the Pilot Mineralen Concentrates [Dutch]. Report 2180, Alterra, Wageningen.

25. Huijsmans, J.F.M., Hol, J.M.G. (2011) Ammonia Emission after Application of Mineral Concentrate to Arable Land and Grassland [Dutch]. Report 398, Plant Research International, Wageningen.

26. Søgaard, H.T., Sommer, S.G., Hutchings, N.J. et al. (2002). Ammonia volatilization from field-applied animal manure - the ALFAM model. Atmospheric Environment 36: 3309-3319.

27. Chalk, T.J. and Smith, C.J. (1983). Chemodenitrification. In: Gaseous Loss of Nitrogen from Plant-Soil Systems, Developments in Plant and Soil Sciences, vol. 9 (eds. J.R. Freney and J.R. Simposn), 65-89. Dordrecht: Springer.

28. Venterea, R.T. (2007). Nitrite-driven nitrous oxide production under aerobic soil conditions: kinetics and biochemical controls. Global Change Biology 13: 1798-1809.

29. Oenema, O., Velthof, G.L., Yamulki, S., and Jarvis, S.C. (1997). Nitrous oxide emissions from grazed grassland. Soil Use and Management 13: 288-295.

30. Bremner, J., Breitenbeck, G., and Blackmer, A. (1981). Effect of anhydrous ammonia fertilization on emissions of nitrous oxide from soils. Journal of Environmental Quality 1: 77-80.

31. Paul, J.W. and Beauchamp, E.G. (1989). Effect of carbon constituents in manure on denitrification in soil. Canadian Journal of Soil Science 69: 49-61.

32. Velthof, G.L. and Mosquera, J. (2011). The impact of slurry application technique on nitrous oxide emission from agricultural soils. Agriculture, Ecosystems \& Environment 140: 298-308.

33. Velthof, G.L., Mosquera, J. (2011). Calculation of Nitrous Oxide Emission from Agriculture in the Netherlands. Update of Emission Factors and Leaching Fraction. Report 2151, Alterra, Wageningen.

34. Stehfest, E. and Bouwman, L. (2006). N2O and NO emission from agricultural fields and soils under natural vegetation: summarizing available measurement data and modelling of global annual emissions. Nutrient Cycling in Agroecosystems 74: 207-228.

35. Weier, K.L., Doran, J.W., Power, J.F., and Walters, D.T. (1993). Denitrification and the dinitrogen/nitrous oxide ratio as affected by soil water, available carbon, and nitrate. Soil Science Society of America Journal 57: 66-72.

36. Ten Berge H. (2002) A Review of Potential Indicators for Nitrate Loss from Cropping and Farming Systems in the Netherlands. Report 31, Plant Research International, Wageningen.

37. Schils, R., Geerts, R., Oenema, J., et al. (2014) Effects of Application of Mineral Concentrate on the Nitrate Concentration of Groundwater. Study in Frame of the Pilot Mineral Concentrates [Dutch]. Report 2570, Alterra, Wageningen. 